Mirai. Estudios Japoneses

ISSN-e: 2531-145X

http://dx.doi.org/10.5209/MIRA.60498

\title{
Viajar para encontrarse a uno mismo. El turismo como estructura narrativa en el cine japonés contemporáneo realizado por mujeres
}

\author{
Irene Raya Bravo루 Francisco J. López ${ }^{2}$
}

Fechas

Resumen. La presente comunicación tiene como objetivo explorar la vinculación existente entre cine y turismo a partir del estudio de tres largometrajes japoneses dirigidos por dos realizadoras. En concreto, estas películas se caracterizan por utilizar el viaje turístico como trama argumental a partir de la cual se estructura el relato; por reivindicar una forma de vida más pausada, sosegada y en contacto con la naturaleza; y por la importancia visual y narrativa de la comida como rasgo definitorio de una región. El estudio parte del análisis cualitativo del discurso audiovisual, utilizando también conceptos propios de la comunicación intercultural, los estudios culturales y los estudios fílmicos, centrándose en cuatro variables: los personajes, los espacios, los efectos del viaje turístico y el estilo audiovisual. Las obras que componen el corpus del estudio son Kamome Diner (かもめ食堂, Naoko Ogigami, 2006), Glasses (めがね, Naoko Ogigami, 2007) y Bread of Happiness (しあわせのパン, Yukiko Mishima, 2012).

Palabras clave: turismo; cine; Japón; directoras japonesas.

\section{[en] Journeys of self-discovery. Tourism as a narrative structure in contemporary Japanese cinema by female directors}

\begin{abstract}
This communication aims to study three contemporary Japanese films directed by female filmmakers, analysing the connection between cinema and tourism as an emergent research topic in Communication Studies. The plots of these films rely on tourist travel as a structural device for the development of the characters and seem to convey a critical discourse regarding conventional lifestyles of present Japan. Using a methodological approach based on the qualitative analysis of the audio visual discourse as well as concepts from Intercultural Communication, Cultural Studies and Film Studies, four variables will be analysed: characters, spaces, effects of the tourist travel, and audio visual style. The corpus of films is composed by the following works: Kamome Diner (かもめ食堂, Naoko Ogigami, 2006), Glasses (めがね, Naoko Ogigami, 2007) and Bread of Happiness (しあわせのパン, Yukiko Mishima, 2012).
\end{abstract}

Keywords: tourism; cinema; Japan; Japanese female directors.

Surmario: 1. Introducción. 1. Introducción. 2. Marco de referencia. 2.1. Confluencias entre el turismo y el cine. 3. Hipótesis, metodología y corpus. 4. Resultados del análisis. 4.1. Análisis de los personajes. 4.2. Análisis de los espacios. 4.3. Análisis audiovisual. 5. Conclusiones

Cómo citar: Raya Bravo, I.; López, Francisco J. (2018). Viajar para encontrarse a uno mismo. El turismo como estructura narrativa en el cine japonés contemporáneo realizado por mujeres, en Mirai. Estudios Japoneses 2(2018), 105-114.

\footnotetext{
Universidad de Sevilla. iraya@us.es

2 Research Center for Modern \& Contemporary Japanese Culture, Nagoya University.
} 
En las últimas décadas, los vínculos entre cine y turismo se han vuelto más patentes, convirtiéndose en dos industrias que se benefician mutuamente mediante su continua interacción. El cine se propone como una herramienta destacada que utilizan las empresas turísticas para promocionar sus productos, sobre todo porque el medio favorece un tipo de propaganda más sutil que supera el rechazo natural de los individuos ante la publicidad directa. ${ }^{3}$ Las películas propician que algunos espacios se conviertan en centros de peregrinaje para los turistas, que en ocasiones deciden sus destinos acorde a los escenarios de sus ficciones predilectas o incluso con la intención de recrear las sensaciones evocadas por sus personajes favoritos.

El presente artículo parte de esta estrecha relación establecida entre cine y turismo para comprobar de qué forma se emplea el viaje dentro de tres películas como vía de construcción narrativa, escogiendo casos de estudio contemporáneos dirigidos por mujeres japonesas. La elección de películas realizadas por cineastas niponas se basa en la necesidad de comprobar si estas dos directoras aportan una sensibilidad diferente en sus creaciones, en un tejido económico y social tan patriarcal como es la industria cinematográfica japonesa. ${ }^{4}$ Aunque cada vez se están reconociendo internacionalmente más cineastas dentro de este entramado industrial, con figuras como Kawase Naomi o Nishikawa Miwa, la proporción frente a los creadores masculinos sigue siendo muy inferior, por lo que deben favorecerse estudios de género que analicen la singularidad de su trabajo.

Como objeto de estudio concreto, nuestro artículo se centra en tres obras firmadas por dos cineastas japonesas, Ogigami Naoko y Mishima Yukiko. El cine de Ogigami se caracteriza por su cuidada visualidad, lo que sin duda se vincula al trabajo de Paradise Café, la compañía de producción con la que colabora desde Kamome Diner, especializada en televisión, publicidad y marketing. Por su parte, Mishima, guionista y directora con trayectoria tanto en cine como en televisión, trata de plasmar en sus películas el valor de la herencia y la tradición, presente en otras obras como Bread of Happiness, Tears of Grapes (ぶどうのなみだ, 2014) o Tsukuroi Tatsu Hito (繕い 裁つ人, 2015).

\section{Marco de referencia}

\subsection{Confluencias entre el turismo y el cine}

Las relaciones entre el cine y el turismo han atraído recientemente el interés de investigadores de diversas disciplinas humanísticas. Si bien es cierto que desde la década de los 90 del pasado siglo ya se venían publicando artículos sobre cómo las personas visitaban los lugares que aparecían representados en obras cinematográficas, ${ }^{5}$ este

3 Aertsen, Víctor U. (2011): "El cine como inductor del turismo. La experiencia turística en Vicky, Cristina, Barcelona". En: Razón y Palabra, n 77.

http://www.razonypalabra.org.mx/varia/77\%204a\%20parte/54_Aersten_V77.pdf [05-06-2016]

4 Blair, Gavin J. (2014): "Japan's Female Directors Making Their Mark in Patriarchal Industry". En: Hollywood Reporter. http://www.hollywoodreporter.com/news/japans-female-directors-making-mark-692070 [Consulta: 03/06/2016].

5 Riley, R. and Van Doren, C.S. (1992): "Movies as tourism promotion: A “pull” factor in a "push" location". En 
objeto de estudio comenzó a ganar relevancia a partir del éxito de sagas cinematográficas como El Señor de los Anillos ${ }^{6}$ o Harry Potter. ${ }^{7}$ La progresiva afluencia de fans, espectadores y viajeros a las localizaciones reales donde se habían rodado los largometrajes sorprendió a los investigadores, quienes empezaron a desarrollar teorías y análisis empíricos para comprender de qué modo afectaba la representación de un determinado lugar en el medio cinematográfico a su valor como posible destino turístico. Actualmente este fenómeno se conoce como «film-induced tourism» ${ }^{8}$ y abarca no sólo el cine sino también la influencia de las series de televisión, los documentales o incluso la animación en los flujos turísticos. Beeton, ${ }^{9}$ en la introducción al número especial de la revista académica Tourism and Hospitality Planning and Development, dedicado al turismo inducido por el cine, señala varios temas que han sido abordados por los investigadores de este área, tales como la motivación de los viajeros a la hora de elegir un lugar que ha aparecido previamente en una obra audiovisual, la necesidad de planificar cuidadosamente las campañas turísticas que se alían con el cine, el impacto en las comunidades locales que puede generar la imagen audiovisual del lugar, o las consecuencias medioambientales de dicha actividad, por citar algunos casos.

Varios autores han propuesto diversas tipologías de turismo inducido por el cine, como por ejemplo Hudson y Ritchie, ${ }^{10}$ que recopilaron datos empíricos sobre cómo la representación de un determinado espacio (ciudad, paraje natural, barrio) en obras cinematográficas o televisivas afectó al número de visitas que recibía por parte de turistas.

\section{Hipótesis, metodología y corpus.}

La presente comunicación tiene como objetivo contribuir al estudio de las conexiones entre el medio cinematográfico y la industria turística. Para ello, se ha optado por llevar a cabo un análisis de la construcción audiovisual y narrativa que se realiza del viaje turístico como experiencia en tres largometrajes japoneses recientes. La hipótesis que sustenta esta aproximación consiste en el hecho de que la representación cinematográfica del viaje turístico puede influir decisivamente en la imagen que los espectadores construyen de los lugares representados y en motivar, en función de las circunstancias, el deseo de visitarlos personalmente. Creemos que, al utilizar el viaje turístico como estructura narrativa a partir de la cual se configuran los eventos de

Tourism Management, 13(3), pp. 267-274; Riley, R. and Van Doren, C.S. (1998): "Movie-induced tourism". En: Annals of Tourism Research, 25(4), pp. 919-935.

6 Buchmann, Anne (2006): "From Erewhon to Edoras: tourism and myths in New Zealand". En Tourism Culture and Communication, 6 (3), pp. 181-189.

7 Lee, Christina (2012): "Have Magic, Will Travel: Tourism and Harry Potter's United (Magical) Kingdom". En Tourist Studies, 12 (1), pp. $52-69$.

8 Riley, R. Baker, D. and Van Doren, C.S. "Movie-induced tourism...", op. cit.; Anul, Kezban. (2013): Film-induced Tourism in Finland. Its Current State and opportunities. Bachelor's Thesis dirigida por Ndegwa Maina y Kristian Siewers. Department: Hotel, Restaurant and Tourism Management Haaga-Helia University of Applied Sciences, pp. 62.

9 Beeton, Sue (2010): “The Advance of FilmTourism”. En: Tourism and Hospitality Planning \& Development, 7 (1), pp. 1-6.

10 Hudson Simon. \& Ritchie, J. R. Brent (2006): "Promoting destination via film tourism: An empirical identification of supporting marketing initiatives". En: Journal of Travel Research, 44, pp. 380. 
la trama, el cine otorga una identidad visual específica a las localizaciones reales y propone modelos de experiencia (por ejemplo, crecimiento personal, sentimiento de transcendencia, encuentros interculturales) a los espectadores.

La metodología utilizada consiste en el análisis cualitativo del discurso audiovisual junto con la aplicación de conceptos procedentes de la Comunicación Intercultural, la Narrativa Audiovisual y los Estudios Culturales. Las variables que se han estudiado son los personajes y los efectos del viaje turístico en ellos, los espacios y la representación audiovisual. Dicho análisis pretende identificar las motivaciones que mueven a los protagonistas a abandonar sus espacios cotidianos, y si el descubrimiento de una nueva realidad socio-cultural a partir del turismo afecta a su vida; el modo en que se lleva a cabo la representación cinematográfica de ciudades, regiones o parajes reales; la ideología subyacente en lo referente al modo de vida de los japoneses en estas obras; y si la ambientación sonora afecta a la percepción de las imágenes visuales que se ofrecen de los espacios.

A la hora de comprobar nuestra hipótesis nos hemos decantado por explorar la vinculación entre cine y turismo a partir del estudio de tres largometrajes japoneses especialmente significativos por compartir entre sí varios aspectos destacables. En concreto, las películas seleccionadas se caracterizan por utilizar el viaje turístico como trama argumental a partir de la cual se estructura el relato; por haber sido dirigidas por mujeres japonesas, lo cual introduce una interesante perspectiva de género; por reivindicar una forma de vida más pausada, sosegada y en contacto con la naturaleza; y por la importancia visual y narrativa de la comida como rasgo definitorio de una región. Las obras que componen el corpus del estudio son Kamome Diner, cuya acción se desarrolla en Helsinki, Finlandia; Glasses, filme que nos muestra las andanzas de varios turistas en una paradisiaca isla de Okinawa; y Bread of Happiness, película ambientada en un paraje rural de Hokkaido. Asimismo, se presta especial atención al tratamiento del espacio como símbolo de identidad, pues mientras Glasses y Bread of Happiness se desarrollan en territorio nipón, Kamome Diner traslada la acción al norte de Europa.

\section{Resultados del análisis}

\subsection{Análisis de los personajes}

Los personajes de los filmes analizados pueden dividirse en tres grupos en función de su procedencia, su actividad profesional y si ejercen o no la actividad turística. Estos tres grupos son: 1) personajes turistas que se caracterizan por desplazarse de su lugar de residencia habitual, 2) personajes hosteleros que gestionan algún tipo de establecimiento relacionado con el turismo (hoteles, albergues, pensiones, restaurantes) en el lugar turístico, y 3) personajes locales que viven habitualmente en el lugar turístico. Las interacciones y conflictos que surgen entre estos tres tipos de personajes conforman la base narrativa de los largometrajes seleccionados.

En los filmes analizados podemos observar que, en muchos casos, el viaje turístico representa para estos personajes una ruptura con su modo de vida habitual y que el destino turístico en sí mismo no es tan importante como el hecho de dejar atrás su ciudad de residencia. Podemos señalar que en las películas dirigidas por Ogigami el 
destino turístico no es el desencadenante del viaje, ya que los personajes no eligen por sí mismos visitar un determinado lugar, sino que, más bien, las circunstancias de sus vidas y el azar terminan llevándoles a los lugares que visitan. Para estos personajes turistas, el lugar visitado viene a ser un espacio de reflexión sobre la vida que han llevado hasta ahora y cómo poder disfrutar de una existencia más satisfactoria.

En el caso de Bread of Happiness, la importancia física del lugar turístico es más relevante. La joven Saito Kaori se deja llevar por la construcción social del turismo como actividad social y culturalmente codificada y, ante la imposibilidad de ir al destino de moda en verano, decide simular su experiencia para no ser criticada por sus compañeras de trabajo. Frente a la importancia social y comercial que el viaje tiene para Kaori, el anciano matrimonio Sakamoto representa una versión más espiritual y personal del viaje. Esta pareja decide visitar Hokkaido porque fue en dicha zona donde, hace casi cincuenta años, se comprometieron en matrimonio. Así pues, para ellos el destino turístico es un espacio vinculado a su trayectoria vital y a sus memorias, en tanto que representa el comienzo de su vida en común. Por ello, no es de extrañar que ese lugar se convierta en el destino de su último viaje puesto que el motivo por el que regresan es morir juntos. Esta intención otorga al viaje un halo espiritual, como si se tratara de un peregrinaje, además de remitir al motivo del michiyuki. ${ }^{11}$ Dicha dimensión espiritual, casi ritual del viaje turístico, también está presente en Glasses a través del personaje de Sakura, quien misteriosamente visita la isla de Okinawa cada año durante un breve periodo de tiempo.

Nuestro análisis ha detectado que los personajes hosteleros de estos tres largometrajes comparten varios rasgos:

1 - Actancialmente, son personajes ayudantes, cuya misión en el relato es contribuir a la felicidad de sus huéspedes o clientes. Este rol mejorador se manifiesta a través de las acciones que realizan en el film, tales como acoger a turistas que no tienen donde alojarse, ofrecer comida, aconsejar sobre los lugares o costumbres locales, y velar por el bienestar físico y emocional de otros personajes.

2 - Representan un punto de encuentro entre los turistas y el destino turístico puesto que son personajes no originarios de la región, pero que, debido al tiempo que llevan viviendo, conocen el idioma, las costumbres y la geografía del lugar. Esto permite que puedan aconsejar, guiar y recomendar a los personajes que llegan.

3 - Los locales que regentan son pequeños establecimientos en los que se ofrece un trato cercano, se prepara comida de calidad, y se cuidan los detalles. Frente a los habituales complejos hoteleros turísticos masificados y caracterizados por el consumo continúo, estos establecimientos intentan ofrecer bienestar anímico.

4 - Del punto anterior se desprende la importancia de la comida. Los personajes hosteleros aparecen en los filmes cocinando diversos tipos de viandas y estas secuencias enfatizan aspectos como la importancia de utilizar ingredientes ecológicos de primera calidad, usar métodos artesanales para la preparación de los platos, y compartir la experiencia de cocinar y comer junto a otras personas. En suma, los

11 El término michiyuki (道行) significa literalmente: “ir al camino, viajar”. Con esta acepción aparece en michiyukibun (道行文), que puede traducirse como “literatura de viajes", pero también se usa para identificar una escena específica de la literatura japonesa. Así, el michiyuki como escena de viaje en la que dos amantes infelices deambulan antes de quitarse la vida fue popularizado principalmente por Chikamatsu Monzaemon (1653-1725) en sus obras de teatro jōruri (de marionetas) durante el periodo Edo. Además del teatro y la literatura, el cine japonés también nos ha ofrecido notorios ejemplos de escenas de michiyuki, tal y como podemos ver en los films Dolls (ドール, 2002) y Hana-bi (はなび, 1997) de Takeshi Kitano. 
filmes recalcan la importancia de disfrutar de la comida con tiempo y plantean una sutil crítica tanto a los restaurantes de comida rápida (no sanos, anónimos) y los restaurantes de lujo (pretenciosos, socialmente marcados) por su clara adscripción a las lógicas capitalistas.

Por último, hablaremos brevemente sobre los personajes locales. Sus roles en los filmes analizados suelen ser menores, pero resultan una pieza interesante a la hora de configurar la experiencia del viaje turístico. En Kamome Diner, dado que la acción del filme se sitúa en el extranjero, los personajes locales son finlandeses que se definen inicialmente por su percepción de las protagonistas japonesas. Así, tenemos a Tommi, un joven universitario capaz de hablar un japonés básico y que no duda en lucir camisetas con motivos japoneses (samurái, geisha) o preguntar por canciones de anime. Se trata del arquetipo internacional del otaku o fan de la cultura japonesa que siente una fascinación y/o amor desmedido por todo lo proveniente de Japón. Por otro lado, también encontramos a varias señoras mayores que miran sin atreverse a entrar en la tienda y bromean sobre los japoneses. Inicialmente, caracterizados narrativamente como personajes hostiles, al final terminan estableciendo una relación intercultural satisfactoria con los personajes japoneses gracias a su apreciación por la comida que se ofrece en el restaurante, así como por la ayuda (en el caso de Liisa o Matti) que reciben de ellos.

En Glasses encontramos solo un personaje local. Se trata de Haruna, la joven profesora de biología del instituto, que desarrolla una relación ambivalente con la turista Taeko. Por último, en Bread of Happiness encontramos a un variopinto número de personajes secundarios locales que vienen a transmitir la idea de comunidad. Todos ellos se conocen entre sí y mantienen relaciones cordiales, ayudándose cuando es necesario. Sin duda, vienen a ser una versión idealizada de las comunidades rurales.

\subsection{Análisis de los espacios}

Como las tres producciones escogidas desarrollan un relato turístico, la representación de los espacios adquiere una especial relevancia dentro de la construcción narrativa de cada una de las películas. Mediante este análisis comprobaremos si esos ambientes alcanzan el suficiente grado de diferenciación para poder ser considerados como personajes, siguiendo los tres criterios de identificación básicos (anagráfico, relevancia y focalización) propuestos por Casetti y Di Chio ${ }^{12}$ para el análisis fílmico. Seguidamente se examinará hasta qué punto estos espacios se han convertido en destinos turísticos atractivos en el contexto real.

Empezando por Kamome Diner, la mayor parte de la película se desarrolla en interior, concretamente dentro del servicio hostelero que Sachie regenta en Helsinki. Con respecto al decorado real, la película se grabó en una auténtica cafetería de Helsinki situada en Pursimiehenkatu 12, cuyo nombre es Kahvila Suomi (Finland Cafe), lo que aporta mayor sensación de realismo a la historia. Ogigami eligió dicho establecimiento y lo redecoró para construir la atmósfera que deseaba, convirtiéndolo en un espacio austero, pero familiar, completamente ajeno a los restaurantes japoneses turísticos que suelen encontrarse en las ciudades europeas. La cafetería cuenta

12 Casetti, Francesco y Federico Di Chio (1991): Cómo analizar un film. Barcelona: Paidós. 
con nombre propio, tiene una importancia fundamental en el relato como punto de confluencia de todas las historias, pero no focaliza la historia, pues su identificación como personaje va absolutamente ligada a Sachie; en el propio filme se expresa la posibilidad de cerrar el local si no funciona, pues salvar ese espacio concreto no es en sí una meta. En ese sentido, el restaurante es una prolongación del personaje de la hostelera, una demostración de su filosofía de vida. Además de la sala de restauración, destaca la presencia del bosque como lugar de regeneración espiritual, pues aunque ocupa una breve secuencia, muestra perfectamente la reconexión de Masako consigo misma, aconsejada además por el joven Tommi, que le comenta que el bosque es el lugar utilizado por los finlandeses para encontrarse a sí mismos; en ese sentido, la influencia de la naturaleza en el espíritu humano no se asocia a un espacio geográfico específico, siendo posible hallar ese vínculo tanto en Japón como en Finlandia. A pesar de ser la única película de las tres analizadas que no se desarrolla en territorio japonés, la recreación de una cafetería nipona en espacio europeo y el uso de elementos culturales afines (tales como el bosque y el salmón) muestran puntos de encuentro naturales entre ambas culturas.

En relación al interés turístico que despierta el espacio representado, en el caso de Kamome Diner, a pesar de que no contamos con estudios cuantitativos, sí que existen tesis de estudiantes universitarios o páginas webs en las que se confirma que cada año numerosos turistas japoneses visitan el establecimiento donde se rodó esta película. Pese a que tras la grabación dicho establecimiento volvió a su estado original, la cafetería se ha beneficiado ampliamente de su utilización como localización del filme y este hecho se recalca con fines publicitarios en diversas webs de turismo. ${ }^{13}$ Anul ${ }^{14}$ señaló que la elección de Helsinki como localización para esta película no se debió a una campaña específica, sino a los esfuerzos personales del director de marketing de la ciudad en aquel momento, por lo que el turismo generado por este filme ha resultado ser más bien casual.

Con respecto a Glasses, al contrario de lo que sucede con el caso anterior, es el ambiente natural el que predomina en la mayor parte de la ficción. Acudiendo a las referencias geográficas reales, aunque no se menciona específicamente de qué isla se trata, Ogigami declaró en una entrevista en un periódico coreano que había grabado la película en una isla llamada Yoronjima (与論島) y explicó que "time passes gently there, twice as slow as the rest of the world". ${ }^{15}$ Se trata de una isla pequeña de unos 20 kilómetros cuadrados con una población de unos 6.000 habitantes, siendo el turismo una de sus principales actividades económicas. Siguiendo los criterios de diferenciación se observa cómo el espacio no posee un nombre propio característico, sí es un cruce de caminos de experiencias personales y en cuanto a la focalización, la isla está al servicio de las actividades de las personas que la pueblan, no funcionando como un ente con personalidad propia; en referencia a este último aspecto, es significativo cómo no se utiliza el escenario vacío, ni siquiera como toma de transición,

13 Entre las páginas turísticas consultadas podemos señalar la web de la cafetería (http://kamome.fi/story/index. html, http://www.visithelsinki.fi/en/stay-and-enjoy/eat/cafe-kahvila-suomi), Tripadvisor (https://www.tripadvisor.jp/Restaurant_Review-g189934-d794744-Reviews-Kahvila_Suomi-Helsinki_Uusimaa.html) y experiencias relacionadas con el espacio concreto de la cafetería

(https://hokuohkurashi.com/note/113505, http://top.tsite.jp/lifestyle/table/i/29297127/) [Consulta: 03/06/2016]

14 Anul, K.: Film-induced Tourism...op.cit. pp.25.

15 Korea JoongAng Daily: "Japanese ajumma spies paradise on a lonely tropical island", 5 de diciembre de 2007. Véase: http://koreajoongangdaily.joins.com/news/article/Article.aspx?aid=2883506 [Consulta: 03/06/2016]. 
apareciendo habitualmente algún personaje en cuadro. La isla no tiene una identidad muy definida, no se vincula a un espacio real concreto, precisamente porque lo que se trata de presentar es un espacio de catarsis, que podría existir en cualquier parte del planeta. Pasando a los espacios interiores representados, aparecen una serie de localizaciones vinculadas a la hospedería (cocina, comedor, dormitorio) que, aunque tienen menor presencia fílmica que la playa, también son importantes para reforzar la idea de vida en comunidad; especialmente relevante es el comedor, que como sucede en Kamome Diner, se presenta como el auténtico lugar de reconexión de la pequeña familia de desconocidos que acude cada año a la isla.

En cuanto al interés turístico despertado por la película, pese a que no hemos podido hallar ningún estudio cuantitativo, existen numerosas webs y blogs, occidentales y japoneses, en los que se recomiendan circuitos para recorrer la isla y visitar los lugares en los que se grabó la película. ${ }^{16}$ Es obvio que el filme de Ogigami atrajo en cierta medida la atención de los espectadores y afectó en muchos casos la decisión de los viajeros.

Por su parte Bread of Happiness se localiza en un pequeño alojamiento rural llamado Café Mani situado en los alrededores del lago Toya en Hokkaido. Se intercalan los espacios interiores y exteriores, aunque la mayor parte de la película se desarrolla dentro del Café Mani, donde Rie y Nao preparan la comida en una especie de ritual diario, especialmente dedicados a la elaboración de distintos tipos de pan. La hospedería tiene nombre propio, es asimismo el núcleo común de todas las historias, pero como sucede con los otros dos casos, está estrechamente ligado al estilo de vida propuesto por sus dueños, más que a las cualidades del propio lugar. El espacio exterior, los alrededores del Lago Toya, se presentan como un entorno idílico para volver a una forma de vida más primaria y tranquila, pero su presencia queda subordinada a los acontecimientos dramáticos que suceden dentro del café. No obstante, también se puede ver cierta influencia de la naturaleza en los personajes: por ejemplo, la luna, que está tratada en la película con ciertos toques de realismo mágico, parece afectar directamente a las emociones de los seres humanos; asimismo, también las estaciones determinan que tipo de pan o comidas cocinan los personajes, de manera que la naturaleza determinaría de este modo su ritmo vital.

En cuanto al atractivo real de los espacios como destino para viajeros, el caso de Bread of Happiness es similar a los previamente comentados y podemos ver cómo los internautas proponen en la red diversas rutas para viajar cerca del lago Toya, y disfrutar de paisajes semejantes a los que se perciben en la película. De hecho, ciertos viajeros recomiendan incluso establecimientos reales ${ }^{17}$ donde se puede disfrutar de una experiencia pareja a la que disfrutan los personajes de la película.

16 Algunas webs cuentan experiencias de turistas mostrando objetos y localizaciones de la película que todavía se conservan: http://guide.travel.co.jp/article/13170/; http://4travel.jp/travelogue/10895544, http://blog.fujitv.co. jp/airmail/E20111215001.html. En otros casos se habla sobre la isla Yoron como escenario de la película: http:// kagoshima-trip.jp/be-en/29/; http://ritou-navi.com/2015/12/01/megane/, https:/www.world.jal.com/world/en/ guidetojapan/jalstaff/detail/cityguidebylocals_yorontou.html. [Consulta: 03/06/2016]

17 En internet pueden encontrarse casos de turistas que comparten y recomiendan sus experiencias en la zona o en el propio espacio: http://guide.travel.co.jp/article/10148/, http://4travel.jp/travelogue/10684535, http://ameblo. jp/ezouma/entry-11534557254.html,https://www.tripadvisor.jp/ShowUserReviews-g670061-d3835657-r26023 8688-Cafe_Gauche-Toyako_cho_Abuta_gun_Hokkaido.html. [Consulta: 03/06/2016] 


\subsection{Análisis audiovisual}

Además de los personajes y los espacios, la forma de representarlos en escena influye en el modo en el que percibimos las cualidades del entorno como potencial destino turístico. En los tres ejemplos se trata de transmitir una sensación, más que de mostrar la grandeza de un destino turístico, lo que en gran medida se consigue mediante determinadas elecciones audiovisuales. Esa sensación ha sido etiquetada en el cine de Ogigami como «iyashi-kei eiga»o «films that provide emotional healing», ${ }^{18}$ entendiendo que son películas que pretenden crear un estado de ánimo positivo, en las que se cuida más la forma que la profundidad narrativa, y orientadas sobre todo al público femenino. Aunque el trabajo de Mishima no reciba el mismo apelativo, se puede observar cómo Bread of Happiness tiene una intención similar y comparte características comunes con la obra de Ogigami.

Desde la perspectiva sonora, las tres películas conceden bastante tiempo al silencio, utilizado como elemento constructor del ambiente pacífico y relajado en el que se mueven los personajes. No se abusa de la banda sonora, ${ }^{19}$ empleada especialmente con tres funciones distintas: como acompañamiento en el montaje de secuencias elaboradas (preparación de la comida en Kamome Diner), para ensalzar escenas icónicas (como ocurre con el emblemático ejercicio del Merci en Glasses) o para identificar a un determinado personaje (como por ejemplo, la mujer extravagante de Bread of Happiness), siempre con un propósito de armonizar, sin sobresalir del conjunto global.

Centrándonos en la óptica visual, el primer aspecto que resalta en los tres casos de estudio es el protagonismo que se otorga a los alimentos, a su elaboración y consumo desde la propia planificación. La actividad en la cocina tiene una relevancia fundamental, transmitida a través de primeros planos, tomas largas y uso moderado de elipsis narrativas, siendo un recurso especialmente recurrente en Bread of Happiness. La minimización de movimiento de cámara o la lentitud de la misma refuerza en las tres películas la idea de un espacio pacífico y relajante, donde los personajes pueden alcanzar un estado de auténtica autorrealización personal.

\section{Conclusiones}

Las películas analizadas en este trabajo se caracterizan por utilizar el viaje turístico como estructura narrativa principal. Este hecho permite mostrar a los espectadores, a través de las experiencias vicarias de los personajes que actúan como turistas en los largometrajes, determinados destinos y experiencias asociadas al viaje turístico.

Nuestro análisis narrativo arrojó como resultado la presencia de tres tipos de personajes (personajes turistas, personajes hosteleros, personajes locales) con diferentes perfiles y acciones en los relatos. Las tres películas analizadas coinciden en recalcar cómo la vida de los personajes turistas cambia tras su paso por los destinos turísti-

18 Laird, Collen (2013): "Imaging a Female Filmmaker: The Director Personas of Nishikawa Miwa and Ogigami Naoko", Frames Cinema Journal, Issue 3. Véase: http://framescinemajournal.com/article/imaging-a-female-filmmaker/ [Consulta: 04/06/2016].

19 En cada caso la firma un compositor distinto: Takahiro Kaneko en Glasses, Tatsuro Kondo en Kamome Diner y Goro Yasukawa en Bread of Happiness. 
cos donde entran en contacto con los personajes hosteleros y los personajes locales. Así pues, el viaje turístico aparece representado en estos filmes no como parte del entramado capitalista que busca explotar tanto los parajes naturales como el tiempo de ocio de los ciudadanos sino como una oportunidad de crecimiento, exploración y transformación. Así, la mayoría de los personajes encuentra durante su viaje una sensación de camaradería, hospitalidad, tranquilidad, serenidad, confort y esperanza que hace que se replanteen su vida anterior y decidan cambiar o aceptar los aspectos que les hacen infelices. Este cambio, que se produce casi de un modo cercano al despertar espiritual, se lleva a cabo gracias a la belleza de los espacios naturales, al consumo de alimentos sanos elaborados de un modo artesanal, la apreciación del tiempo personal y el establecimiento de relaciones interpersonales significativas basadas en la empatía.

Asimismo, el análisis de los espacios y de la representación audiovisual ha revelado patrones similares en las tres películas reforzando el mismo espíritu transmitido por la construcción de los personajes. Por un lado, la importancia del contacto con una forma de vida más natural no es solo expuesta por las vivencias de estas personas, sino que también se transmite a través de los espacios y la propia puesta en escena. El nexo común en los tres casos es la comida, su elaboración y el acto comunitario de compartirla, dedicándole gran cantidad de tiempo cinematográfico a todo el proceso como parte fundamental de la vida de todos los personajes. El uso de planos de larga duración y la minimización de los movimientos de cámara también está al servicio de crear un ambiente de tranquilidad y relajación vinculado al propio viaje. Por otro lado, aunque dos de las producciones se desarrollan en Japón y otra de ellas en Finlandia, no existen diferencias significativas a nivel audiovisual ni temático, de modo que la identidad nipona está representada en las tres películas con un peso narrativo similar.

En cuanto a la posibilidad de que los largometrajes analizados puedan contribuir a que los espectadores decidan desplazarse físicamente a los espacios representados en los filmes, creemos que estos tres títulos pueden funcionar como inductores de turismo, aunque no siempre de forma claramente intencional. Ya se ha comentado que en el caso de Kamome Diner, los turistas realizan peregrinajes hasta el auténtico local finlandés, como también sucede con viajeros que acuden a la isla de Glasses; más significativo es el caso de Bread of Happiness, puesto que en vez de buscar el referente real donde se rodó el filme, los usuarios buscan espacios reales donde experimentar las mismas sensaciones transmitidas por el film. Es decir, la película actúa como catalizadora de las expectativas de los turistas y ello evidencia hasta qué punto el discurso cinematográfico puede moldear los intereses de los viajeros e influir en sus valoraciones o apetencias a la hora de desplazarse. En definitiva, los tres casos proponen el turismo como experiencia vital de crecimiento personal, más que erigirse como destinos específicos en sí.

Como conclusión, las cineastas Ogigami y Mishima nos proponen con sus largometrajes un cambio de actitud y valores, es decir, nos alientan a cuestionar la importancia de la espiral de trabajo y consumo propia de las sociedades capitalistas actuales al tiempo que nos invitan a probar formas de vida más relajadas, naturales, sostenibles, colectivas y armoniosas. 